\title{
Perception and Motivation of National Health Insurance Program Participation in Bogor
}

\author{
Fika Hardini Lestari* \\ Department of Family and Consumer \\ Sciences, Faculty of Human Ecology, \\ Bogor Agricultural University
}

\author{
MD Djamaludin \\ Department of Family and Consumer \\ Sciences, Faculty of Human Ecology, \\ Bogor Agricultural University
}

\begin{abstract}
The objective of the study was to analyze the perceptions and motivation of National Health Insurance Program (NHIP) in Bogor. This research design was cross sectional study with 140 respondents by non probability sampling method with convienience \& accidental sampling technique. Data were collected by questionnaires filled out directly by the participants. The perception of NHIP participants were in the moderate category and the perception of the respondents which was not the participants of NHIP was in the bad category. Motivation of NHIP was in middle category while the respondents were not a NHIP and the motivation was categorized low. The test results showed that the age, perception and motivation had a significant positive relationship. The results showed that the perception and motivation had a very significantly positive effect on the participation of National Health Insurance Program.
\end{abstract}

Keywords: perception, motivation, national health insurance 


\section{Introduction}

Health is a basic right of all citizens. Under the Law of 1945 Article 34, paragraph 3 of the National Economy and Social Welfare, the state is responsible for protecting its citizens, including responsible for the provision of health care facilities and public service facilities which are decent. In accordance with Law No.40 of 2004 on National Social Security System (NS3) social security systems is the procedure for the organization of social security programs by several agencies of social security. This system covers the entire population of Indonesia, regardless of whether they are workers in the formal or informal sectors, and even unemployment (Rapper 2008).

The National Health Insurance (NHI) developed in Indonesia is part of the NS3 organized through social insurance mechanisms aimed at keeping the entire Indonesian population covered by the insurance system. Indonesian state towards Universal Health Coverage (UHC) based on the Health Law No. 36 of 2009 Article 13 states that every person is obliged to participate in the social health insurance program. The purpose of health insurance for the entire population of Indonesia is to protect health financing problems and to meet the basic needs of the public health. The assurance given to everyone who has registered themselves as participants in a National Health Insurance and pay dues or for participants Beneficiaries Contribution in which the costs have been paid by the government. National Health Insurance provides comprehensive benefits with affordable premiums and implements a quality control system and cost control. NHI guarantees the certainty of health care costs that can be used in all parts of Indonesia, for all the people of Indonesia whose costs is under control so that participants can get health care at any health facility so that the first level, membership is mandatory. On January 1, all health insurance program that had been implemented by the government, such as Health Assurance of Government Employees, Social and Labor Assurance, Military, police, and NHI were integrated into the social security agency (SSA).

Social Security Agency (SSA) is a public legal entity formed to administer a social security program consisting of Health SSA and employment SSA. Health SSA organizes health insurance program aiming at providing health care for all participants. Participants of National Health Insurance are all Indonesian people, including foreigners who have worked for a minimum of six months in Indonesia and have paid contributions or dues paid by the government to the nature of membership which is mandatory even though the person has already had other health insurance. (Ministry of Health 2013)

According to the official website release of Health Social Security Agency (SSA) Per-date June 17, 2016 there have been 167.199.551 participants with number of health facilities per - dated July 1, 2016 as many as 19.096 which consists of 9.815 health centers, 711 Indonesian National Military clinics, 569 Police clinics, .524 pratama 3clinics and 4.477 doctors practice ${ }^{2}$.

According to the regulations of the Minister of Health Number 28 Year 2014 on guidelines for the implementation of the National Health Insurance Program chapter 3 related to the participants and membership. Participants in the National Health Insurance Program consist of two groups of participant, namely participants Contribution Recipient and participants not Contribution Recipient. 
Based on the records of SSA membership in Bogor until april 2016 had registered himself as a NHI participant Bogor only with 674.614 inhabitants of the total number of 6.361 .869 people in the district and the Bogor city . Participants of National Health Insurance are not the recipient of contributions which have increased since 1 April 2016. The reason for the fee increasement of SSA among others is to reduce the deficit expected claim payments and improve service quality. The fee increase for class I went up from IDR 59.500 per person per month into IDR 80.000 per person per month, for class II, it went up from IDR 42.500 per person per month to IDR 51.000 per person per month, for class III, it went up from IDR 25.500 per person per month to IDR 30.000 per person per month. Contribution NHI for Contribution Recipient participants will raise to IDR 23.000 per person per month from the previous IDR 19.225. In the social security agency Bogor City will enforce penalties for participantsof NHI delinquent monthly dues are a maximum of 30 million for the participants of the National Health Insurance.

There were not many public responses to the National Health Insurance Program through the Social Security Agency (BPJS) of health. Citizens who register as a participant BPJS find that the community is less enthusiastic to participate the insured people. It is against the background by poor health care that received in the past when using social security. Fear profound dilemma leads to the conditions and a lack of awareness of the importance of social security health at work. The fear was related to the participants' social security rights. Ultimately arises a sense of surrender to reach health services (Sadewo and Wahyuning 2015).

Perceptions of everyone to an object will vary. Therefore, the perception has subjective trait. Perceptions are shaped by a person affected by the thoughts and the surrounding environment. A perception that is generated can be both positive and negative stimulus. According to Kotler (2002) each person has a different perception of the same object. Each individual received hundreds of stimuli or stimulus into one's senses. Not all stimulus paid or remembered, it was because someone performed processing of information.

According to Lindenthal (2004), community perception towards government institutions is not very positive, especially against Social Security. Many people consider that the Social Security premium is too high when compared to the expected benefits, as well as the procedure to propose a claim for benefits is sometimes unpleasant. Based on research conducted by Christian et al (2006), the public perception of the Health Insurance Program for the Poor Community (HIPPC), it is influenced by several factors. Internal factors that is education, knowledge, experience, and motivation. Motivation factors give strong influence on perceptions of HIPPC.

Motivation arises because of the feeling needed by consumers. Requirement (motive) arise because consumers feel discomfort (state of tension) between which should be felt and perceived that actually means. The feeling felt can encourage someone to take action to meet that needs. Stimulation occurs because of the gap between what is perceived with what should be perceived so that consumers feel their recognition of the need. Recognition of the need will cause distress to the consumer so that encouraging him to do actions that have aim (goal 
directed behavior) is important. Such actions can be various kinds such as consumers seek information, consumers talk to a friend, relatives or go to the store, and consumers buy products or services to meet those needs. Such actions will lead to the achievement of the consumer goal or the fulfillment of the consumer needs. Consumer motivation conducted by the manufacturers is closely linked to consumer satisfaction. (Sumarwan 2011).

Based on these descriptions, it is important to see the perceptions and motivations to participation in National Health Insurance Program (NHIP) in the Bogor city. Research was conducted to: 1) identify differences of characteristic respondents, perception and motivation in the National Health Insurance Program based on program participation NHP; 2) analyze the relationship between the characteristics of the respondent, perceptions, and motivations to participation in NHIP; 3) analyze the factors that influence to participation of NHP.

\section{Method}

The research design used in this study was cross-sectional study. The choice of location in the research was conducted purposively, that is, Bogor city. The population in this study was that Bogor community with a minimum age of 19 years is as a productive working age according to Acts 13 of 2003. Respondents in this study as many as 140 people were selected by convenience sampling to obtain data from respondents whose participants of National Health Insurance Program will be undertaken in hospitals that receiving patients of NHISSA in Salak hospital, Bogor City Government hospital, and PMI Hospital and accidental sampling to obtain data from respondents who not are participants of National Health Insurance.

Types of data collected in this study were primary and secondary data. Primary data were obtained from the results of the respondents self administered (interview) with a questionnaire tool covering respondent characteristics (age, education, occupation, and income), the perception of National Health Insurance Program, and motivation to involve in the National Health Insurance Program. Instrumen of perception is modificated from the study of Widhiastuti (2015) with 10 number of statement items that have been tested with cronbach alpha reliability of 0,875 . Motivation instrument is modified from the study of Tiaraningrum (2014) with 5 number statement items that have been tested reliability with cronbach alpha of 0.930. Answers to the perception and motivation were measured using a 1-5 point Likert scale ( 1 = Strongly disagree, 2 = Disagree, $3=$ Neutral, $4=$ Agree, $5=$ Strongly agree). Analysis of the data obtained is by using descriptive test used, that are frequency, average, maximum value, minimum value, standard deviation, and cross tabulation. Descriptive analysis is used to describe the distribution of respondents based on individual characteristics (age, education, occupation, and income) as well as associated with variables research about perception and motivation. Correlation test is used to analyze the relationship between variables, different T-test, and logistic regression test. 


\section{Result and Discussion}

\section{Characteristic of Respondent}

The characteristics of most respondents were in the range of 19-24 years. The average age of respondents NHI participants was 30.54 years with a standard deviation of 12:28, which is higher than that of non-participants, that is, 23.47 years $(\mathrm{sd}=3.53)$. Table 3 shows the respondent age of the NHIP participants who is mostly around the age of 19-24 years as many as 41 people (58.6\%). Age of the respondents who are not NHI participants also be in the range of 19-24 years as many as 57 people $(81.4 \%)$. Only a three of respondents $(4.3 \%)$ are not NHI participants who have age range of 36-50 years. Based on different test of the age of the participants and not participants statistically significantly different at $p$ $<0.01$. Age of respondents are grouped into five categories: early adult, old adult, middle-aged, elderly, and old elderly that adjusted according to the consumer's life cycle Sumarwan (2011). Age 20-55 years is the target of life insurance protection and already has economic value of life (Purba 1992). Therefore, it is important for someone to follow the National Health Insurance Program that aims to provide protection from the financing problems of health with social insurance mechanisms.

Respondents in this study were from six levels of formal education in Indonesia with the largest percentage $(41.4 \%)$ that have the highest education level until high school which is equal to the respondent participants of National Health Insurance Program. Respondents who are not participant of National Health Insurance Program also have the percentage of education level up to the largest untill high school (48.6\%). According to Sumarwan (2003), education level of individual will affect the embraces values, way of thinking and way of looking at something.

The type of respondent work who were participants in National Health Insurance Program was dominated by private sector employees (40\%). Respondents were not recipients of National Health Insurance which is also dominated by private sector employees $(50 \%)$. Average revenues earned per month of respondent of NHIP participants is $\mathrm{Rp} \mathrm{3.093.528.} \mathrm{Meanwhile,}$ respondents' average income are not participants of program is Rp 3.148.184. Based on the different test results there is no significant difference between income of participants and non-participants at $\mathrm{p}<0.05$.

\section{Perception}

The results showed that, overall, more than half of respondents who were the participants of NHIP $(51.4 \%)$ had a perception in the medium category and more than half of respondents are not participants $(70.0 \%)$ have a perception of NHI program in the category of bad. This is because the participants of NHIP have better understand of the program and has experience in the utilization of NHIP. In addition, it can be seen from the respondents answering who stated strongly agree in answering the related statements the perceptions of NHI service, including registration procedures and the availability of patient room. Average perception scores who are not NHIP participants (mean $=49.57$; std $=8.14$ ) lower than respondents who are the NHIP participants ( mean $=60.04$; std $=9.78)$. Thus, 
the results of different test shows that there are significant differences between the scores of perception among NHI participants and non-NHI participants ( $p<0.01)$ (Table 1).

Table 1 Distribution of respondents by perception and statistics related to the NHIP

\begin{tabular}{lccc}
\hline $\begin{array}{c}\text { Perception category of fasting National Health } \\
\text { Insurance Program }\end{array}$ & $\begin{array}{c}\text { Participant } \\
(\mathrm{n}=70)\end{array}$ & $\begin{array}{c}\text { Non- } \\
\text { Participant } \\
(\mathrm{n}=70)\end{array}$ & $\begin{array}{c}\text { Total } \\
(\mathrm{n}=140)\end{array}$ \\
\hline Poor ( 38-52) & 22.9 & $\mathbf{7 0 . 0}$ & $\mathbf{4 6 . 4}$ \\
Medium (53-66) & $\mathbf{5 1 . 4}$ & 28.6 & 40.0 \\
Good (67-80) & 25.7 & 1.4 & 13.6 \\
\hline Mean \pm std & $60.04 \pm 9.775$ & $49.57 \pm 8.142$ & $54.80 \pm 10.388$ \\
\hline Min - max & $38-80$ & $32-75$ & $32-80$ \\
\hline Different test & & $0.000^{* *}$ & \\
\hline
\end{tabular}

Description: ** significant at $\mathrm{p}<0: 01$

Perceptions of National Health Insurance Program were grouped into three categories: poor, moderate, and good. The results showed that the perception of participants of NHIP was at 77.1 percent while non-participants of the National Health Insurance Program has a bad perception of the NHIP amounted to 61.4 percent. The medium level of perception are reflecting that respondents adequately understand the benefits of National Health Insurance Program while the poor level of perception means that the respondents do not understand the benefits of National Health Insurance Program and have a negative view to NHIP due to the stimulus that received in the form of relevant information that by becoming NHIP participant is not necessarily to find it easy to gain access to health facilities, complicated registration procedure and process of expense claims. The level of a person's perception related to past experiences that both health insurance program nasional. According to Sutisna (2001) brand image represents the entire perception of information and past experience to the brand. The results are consistent with research by Mulupi et al (2013) who states that bad perception on the National Health Insurance Program in Kenya happened because of the of poor services provision in health facilities, long waiting times, inadequate benefits and high payments. Therefore, perceptions of information delivered were about National Health Insurance depending on who individual who receives is.

\section{Motivation}

The results of the study show that in Table 2, it is described that most participants respondents of a National Health Insurance has motivated at the medium category (71.4\%) and the group of non-participants of National Health Insurance have the motivation categorized low $(57.1 \%)$ and moderate $(42.9 \%)$. It can be seen from the answers of respondents who answered statement strongly disagree with the motivation of the participation of National Health Insurance Program, among others, the socialization statement of the National Health Insurance Program and reduce the financial burden of the family. The average scores of respondent who are not NHI participants about the motivation of 
National Health Insurance Program participation $($ mean $=49.64$; std $=11958)$ were lower than average of motivation score in NHI participants (mean $=64.07$; std $=13$ 305). Thus the different test results showed that there were significant differences between the scores of motivation respondents NHI participants and non- NHI participants $(\mathrm{p}<0.01)$ in

Table 2 Distribution and statistical respondents based on motivation program participation in NHI

\begin{tabular}{lccc}
\hline \multicolumn{1}{c}{ Motivation Category } & $\begin{array}{c}\text { Participants } \\
(\mathrm{n}=70)\end{array}$ & $\begin{array}{c}\text { Non- Participants } \\
(\mathrm{n}=70)\end{array}$ & $\begin{array}{c}\text { Total } \\
(\mathrm{n}=140)\end{array}$ \\
\hline Low (15-50) & 20.0 & $\mathbf{5 7 . 1}$ & 38.6 \\
Medium $(51-75)$ & $\mathbf{7 1 . 4}$ & 42.9 & $\mathbf{5 7 . 1}$ \\
High (75-100) & 8.6 & 0 & 4.3 \\
\hline Mean \pm std & $64.07 \pm 13.305$ & $49.64 \pm 11.958$ & $59.86 \pm 14.535$ \\
\hline Min - max & $25-100$ & $15-70$ & $15 \pm 100$ \\
\hline Different Test & & $\mathbf{0 . 0 0 0 * *}$ & \\
\hline Description: $* *$ significant at $\mathrm{p}<0: 01$ & &
\end{tabular}

Motivation is a support for someone to participate in a National Health Insurance Program. Results showed that participants of a National Health Insurance Program have medium motivation by 71.4 percent, while participant of non-National Health Insurance Program have little motivation at 57.1 percent. Low motivation means that the encouragement of respondent to participate in a National Health Insurance Program is still low. The existence of motivation encourages people to participate in National Health Insurance Program. High motivation indicated by statement that health is important issues so that respondent follows the National Health Insurance Program.Therefore, following the National Health Insurance Program could meet the needs of physical protection. Physical safety needs will cause a psychological sense of security so that consumers do not feel anxious and worried and threatened his life wherever they are (Sumarwan 2011).

\section{Relationships of Respondents' Characteristics, Perception, and Motivation with the Participation in National Health Insurance Program}

Correlation test results in Table 3 showed that the participation of National Health Insurance Program associated with age, perception and motivation. There is a tendency that the older the person, the more participation of National Health Insurance Program would be. Perceptions had significantly positive results with the participation of National Health Insurance Program. It is indicated that higher the perception of respondents, the higher participation of National Health Insurance Program will be. In addition to age and perception, motivation also had significant positive results with the participation of National Health Insurance Program. This shows the higher the motivation of the respondent, the higher participation of National Health Insurance Program will be. 
Table 3 Correlation between characteristic of respondent with the participation of National Health Insurance Program

\begin{tabular}{ccc}
\hline \multirow{2}{*}{ Characteristics of Respondents } & \multicolumn{2}{c}{ The participation of the National Health Insurance } \\
\cline { 2 - 3 } & Coefficient & Sig \\
\hline Age & $\mathbf{0 . 2 1 0}$ & $\mathbf{0 . 0 0 6}$ \\
Education & 0.029 & 0.369 \\
Income & 0.053 & 0.267 \\
Occupation & -0.032 & 0.354 \\
Perception & $\mathbf{0 . 5 2 1}$ & $\mathbf{0 . 0 0 0}$ \\
Motivation & $\mathbf{0 . 5 1 4}$ & $\mathbf{0 . 0 0 0}$ \\
\hline Note: $*$ ) significant at the level $<0.10$ (one-tailed) & $* *$ significant at the level of $<0.05$ (one-tailed)
\end{tabular}

The results showed that the age has a very significant correlation $(\alpha=$ 0.006) and a positive value to the participation of National Health Insurance Program. This suggests that the more increasing a person's age, the more participations of National Health Insurance Program would be. This is in line with research by Siswoyo (2015) and Widhiastuti (2015) which states that more individuals older, the more risk of health and vulnerable against the disease so that it appears awareness to be a participant of National Health Insurance.

Perception has a significant positive correlation $(\alpha=0.000)$ with the participation of National Health Insurance Program. Stimulus received by the respondents was expected to form a perception of the participation in National Health Insurance Program. This is in line with research by Jehu et al (2012) which stated that the community participation in health insurance registration and retaining a decision to become volunteer participant because they have a good perception about the benefits, convenience, and contributions that paid.

Motivation is another variable that has a very significant correlation $(\alpha=$ 0.000 ) and a positive value to the participation of National Health Insurance Program. It indicates that more higher the person's motivation, the participation of National Health Insurance Program is increasing. This is in line with research of Tiaraningrum (2014) that motivations related to the participation of National Health Insurance Program because of the ease of registering, socialization, information received, the availability of health facilities, health care costs are covered, and protection in the old days. In addition, the research of Rumengan et al (2015) states that if the public perception about health programs such as NHIPSSA is good, it will encourage people to use it.

\section{Factors Affecting to Participate in National Health Insurance Program}

The results of binary logistic regression analysis showed that the value of $\mathrm{R}$ square Nagelkerke in this study amounted to 53.1 percent influenced by variables studied, while 46.9 percent were influenced by other variables that not studied. In addition, Table 4 describes the tendency of respondents to participate in National Health Insurance Program related positive with the perception of National Health Insurance Program. This indicates that respondents who had affairs with the participation of National Health Insurance Program are based on a good the perception of National Health Insurance Program has opportunity for participate in National Health Insurance Program 1,106 times greater than that in 
the respondents who have bad perceive National Health Insurance Program. Respondents who have high motivation has opportunity to participate National Health Insurance Program 1,067 times greater than the respondents who have low motivation. Thus, in general it can be said that the chances of respondents to participate in National Health Insurance Program influenced by perceptions and motivations.

Table 4 Effect of the characteristics of respondents, perception and motivation towards participation on NHIP

\begin{tabular}{llrr}
\hline Variable & Beta & \multicolumn{1}{l}{ Sig. } & Exp(B) \\
\hline Age of respondents (Year) & 0.108 & 0.016 & 1.114 \\
Education of respondents $(0=$ Non-higher education, $1=$ & 0.338 & 0.479 & 1.402 \\
higher education) & & & \\
Occupation of respondents $(0=$ not working, 1 = working) & 1.159 & 0.121 & 3.187 \\
Income (IDR) & 0.000 & 0.110 & 1.000 \\
Perception & 0.390 & $\mathbf{0 . 0 0 2}$ & 1.106 \\
Motivation & 0.247 & $\mathbf{0 . 0 0 1}$ & 1.067 \\
\hline Nagalkerke R square & & 0.531 & \\
\hline Cox \& Snell $\mathrm{R}^{2}$ & & 0.339 & \\
\hline $\mathrm{N}$ & & 140 & \\
\hline Note: $*$ significant at the level of $\mathrm{p}<0.05, * *$ significant at $\mathrm{p}<0.01$ & &
\end{tabular}

Regression analysis showed that perceptions and motivations had influence on the participation of National Health Insurance Program. This means the respondent opportunity to participate in National Health Insurance Program was influenced by the perceptions and motivations. This is supported by results of Noviansyah et al (2006) which stated that there are internal and external factors that affect the community perception to Health Insurance Program for the community. Internal factors were influenced by education, knowledge, experience and motivation. While external factors that influence public perception is the socialization of the Health Insurance Program. Motivation is the most dominant factor because getting health services is one of the efforts to meet basic needs. As for age, education, occupation and income do not affect the participation of National Health Insurance Program. It's not go along with the research of Barnighause et al (2007) concerning the determinant factors which significantly affect the willingness of people to participate and pay for health insurance; age, sex, income, past medical experience, employment, migration status, and past experience.

This study has limitations, that is, the demographic characteristics, in this study these characteristics tend to be homogeneous as in the case of education is high school / equivalent, job, income that can make research data is not representative. Besides the selection of the study population was too wide so that the present study only describes the respondents in the study can not be generalized. 


\section{Conclusion}

\section{Conclusion and Recommendation}

The study involved 140 respondents in the age of the respondents who were in the range of 19-65 years. A total of 98 respondents are in the category of early adulthood. The education level of respondents are located mainly in the high school graduate/equivalent. Work as a private employee were dominated respondent in this research. Some of 56 percent of respondents have an income of between IDR 3.500.0001 -6.500 .000 with the average income of all respondents is IDR 3.121.050.

The overall perception of respondents participants of National Health Insurance Program was in the category of enough while the respondent is not participant in a National Health Insurance Program participants. This is considered into bad category. A total of 40 respondents disagreed with the National Health Insurance Program, they do not feel worried about the cost of treatment.

Motivation of overall participant respondents was in the moderate category and the respondents are not participants who have little motivation to the participation of National Health Insurance Program. A total of 37 people stated quite agree with the statement of motivation for participation in National Health Insurance Program because healthy is important so that they followed the National Health Insurance Program.

Aspects of the characteristics of respondents test had only age that has positively significant relationship with the participation of the National Health Insurance Program. The perception variables has a positive significance with the participation of the National Health Insurance Program. Likewise, the motivation variables have a significant positive correlation with the participation of National Health Insurance Program. The results of logistic regression showed that age, education, employment, income, perception and motivation influence the participation in National Health Insurance Program by 53.1 percent, while the rest influenced by other factors that was not researched (46.9\%).

\section{Recommendation}

The results of this study indicated that the perception was positively associated with the motivation and both have an important effect with the participation of the National Health Insurance Program. Thus for the participation of society in the National Health Insurance Program, the government or the concerned party need to improve the public perception with more dissemination of information related to understanding NHIP-SSA. The benefits followed the National Health Insurance, the benefits of being participants of National Health Insurance Program, and ordinances registration of participants of the National Health Insurance by using SSA. Thus, the program is expected to improve retention on purpose.

The population in the study was too broad with a large area coverage. Thus, for further research, it can determine the location and population of more minimized as by specific districts or strip so that it can use the technique of taking a random sampling. 


\section{Reference}

[SSA] Social Security Agency. (2014). Free Service for National Health Insurance Participants . Jakarta (ID): NHIP

[Ministry of Health] Health Ministry of The Republic of Indonesia. (2013). The FAQ Handbook of NHIP. Jakarta (ID): Health Ministry of Indonesian Republic.

Haile, M., Ololo, S.., Megersa, B. (2014). Willingness to Join Community-based Health Insurance among Rural Households of Debub Bench District, Bench Maji Zone, Southwest Ethiopia.BMC public health [internet].[di unduh 2015 Desember 18]; 14(01): London. Tersedia pada :https://bmcpublichealth.biomedcentral.com/articles/10.1186/1471-2458-14$\underline{591 .}$.

Jehu-Appiah, C., Aryeetey, G., Agypong, I., Spaan, E., Baltussen, R (2012). Household Perceptions and Their Implications for Enrollment in The National Health Insurance Scheme in Ghana. Health policy and planning [internet]. [diunduh 2015 desember 18]; 27(03): Nijmegen. Tersedia pada :http://www.ncbi.nlm.nih.gov/pubmed/21504981.

Kristiani, N., Sari, F., Dewi, T. (2006). Public perception of health insurance program for poor people (03) [Internet]. [Downloaded on 07 December 2015]; 22 (03): Yogyakarta. Available at: http: //journal.ugm.ac.id/bkm/article/view/3648/3130.

Lindenthal R. 2004. The Challenge of Social Protection For all. Jakarta (ID) : UNSFIR

Macha, J., Kuwawenaruwa, A., Makawia, S., Mtei, G., Borghi, J. (2014). Determinants of Community Health Fund Membership in Tanzania: a Mixed Methods Analysis. BMC Health services research [internet]. [di unduh 2015 Desember 18]; 14(538): London. Tersedia pada :http://www.ncbi.nlm.nih.gov/pubmed/25411021.

Mulia, W., Sadewo, F. (2015). Awareness about social health insurance postimplementation of health social security agency of in tulungagung. paradigm [Internet]. [Downloaded in 2015 December 24]; 03 (02): Surabaya. Available at: http: //ejournal.unesa.ac.id/index.php/paradigma/article/view/11463.

Mulupi, S., Kirigia, D, Chuma J. (2013). Community perceptions of health insurance and their preferred design features: implications for the design of universal health coverage reforms in Kenya. BMC [internet]. [diunduh pada 13 juli 2016]; 13(474): Kenya. Tersedia pada :http://www.ncbi.nlm.nih.gov/pubmed/24219335.

Nasution. (2003). Methods Research (Scientific Research). Earth Literacy: Jakarta.

Nosratnejad, S., Rashidian, A., Mehrara, M., Akbari, S.A., Mahdavi, M., Moeini, M. (2014). Willingness to pay for the social health insurance in Iran. Global Journal Of Health Science [internet]. [downloaded at 2015 desember 18]; 6(05): Teheran. Available at :http://www.ncbi.nlm.nih.gov/pubmed/25168979.

Purba, R. (1992). Understanding Insurance in Indonesia. Jakarta (ID): PT. Pustaka Binaman Pressindo. 
Puspitawati, H., Herawati, T. (2013). Family Research Methods. Bogor (ID): IPB Press.

Putri, A.E. (2014). Series Book 1: Understanding the Social Security National Social Security System. Jakarta: CV Komunitas Pejaten Mediatama

Rapper, M. (2008). State without social security: three pillars of social security in Australia and Indonesia. RO Tambunan, editor. Jakarta (ID): TURC

Rumengan, D.S.S., Umboh, J.M.L., Kandaou, G.D. (2015). Factors related to the utilization of health services at health clinics NHIP participants in Paniki Mapanget Down District of Manado City. JIKMU (01) [Internet]. [Downloaded 2016 August 01]; 5 (01): Manado. Available at: http: //ejournal.unsrat.ac.id/index.php/jikmu/article/download/7180/7388.

Setiadi, N.J. (2008). Consumer Behavior Concepts and Implications for Strategy and Marketing Research

Siswoyo, B.E. (2015). Awareness of deposit informal workers on national health insurance program in the Yogyakarta Special Province of Indonesia's. Journal of Health Policy [Internet]. [Downloaded on 24 June 2016]; 04 (01): Yogyakarta. Available at: http: //prisma.lppm.ugm.ac.id/doc/597.

Sumarwan, U. (2011). Consumer Behavior: Theory and Practice in Marketing. Bogor (ID): Ghalia Indonesia.

Sutisna. (2001). Consumer Behaviour and Marketing Communication.Bandung (ID): PT Youth Rosdakarya.

Tiaraningrum, R. (2014). Descriptive study of motivation and personal reference of independent national health insurance participants in disadvantaged areas, Mojongso, Surakarta Village. [thesis]. Surakarta (ID): University of Surakarta Muhamaddiyah

Widhiastuti, I.A.P. (2015). Relationships of sociodemographic, perceptions, and socialization factors with the membership outpatient in the national health insurance program independently in East Denpasar community health center I [thesis]. Denpasar (ID): University of Udayana 